\title{
Analysis of wind power potential as an electricity source for safety light and sign on limestone mining hauling road
}

\author{
Ikhsan Purnama ${ }^{l}$ and Muhammad Imran Hamid ${ }^{1 *}$ \\ ${ }^{1}$ Andalas University, Electrical Engineering Department, 25163 Padang, West Sumatera - Indonesia
}

\begin{abstract}
A work accident can occur anytime and anywhere to the worker if they take unsafe action and are in an unsafe condition. Mining areas located in the hills have unsafe conditions for operating heavy equipment, such as steep terrain conditions, slippery roads, and foggy weather, and lack of lighting. Installation of light assign is the right step in reducing work accidents at night, foggy and rainy weather. Measurement of wind data and calculation of wind potential statistically using Weibull distribution. The parameter values of scale and shape are 1.67 and 1,71 respectively, with an average wind speed of $1,49 \mathrm{~m} / \mathrm{s}$ and the wind power potential of $3.14 \mathrm{~W} / \mathrm{m}^{2}$. Based on measurement and analysis results, this quarry always gets wind gusts both day and night, so it has the potential to take advantage of wind energy either on a small turbine scale or in small and medium electric power.
\end{abstract}

\section{Introduction}

Limestone is a raw material for cement production. In the mining of limestone, there are stages of the process, they are land clearing, drilling, blasting, loading, hauling, crushing, and conveying. Each of them has a high risk of work accidents. The mining process cannot be separated from the worker factor must also be considered, by guaranteeing health and safety and preventing accidents.

Work accidents can occur to workers anytime and anywhere if they take unsafe actions and they are in unsafe conditions. On the other hand, a work accident is undesirable even and often unpredictable, which can cause loss of a good time, possessions, or property or loss of life that occurred in a work mining process or related to it. Therefore, as soon as possible work accidents are minimized to make the whole mining process run smoothly and the safety of workers is protected [1].

The hauling process has a high level of risk of work accidents in the mining world which have a high impact on death and injury, as well as financial losses in the form of repairs, replacement parts, and downtime [2]. Mining areas located in the hills have unsafe conditions for operating heavy equipment, such as steep terrain conditions, slippery roads, and foggy weather, and lack of lighting. The performance of a truck driver or operator depends on fatigue, concentration, skills, training experience [2][3][4]. The ability to drive is often impaired by the failure of the work system on the machine and the environment such as heavy fog, dust, and rain [2][3]. Installing safety lights as a sign and powered by the wind as electricity is one of the right solutions in reducing work accidents at night, foggy, dusty, and rainy weather on hauling roads. Besides that, the safety light can be a warning sign of an earthquake for vehicles while going to pass through cliffs and ravines.

The wind is renewable energy, abundant, and easy to obtain. Wind energy can be converted into mechanical and electrical energy by a wind turbine. Wind intensity is different at each location on the earth, depending on time and position toward sea level. Wind dynamics can be studied by applying the probability density function or probability distribution [5]. This distribution can be used for modeling wind speed in various regions.

In probability theory and statistics, the Weibull distribution is a continuous distribution that was first introduced by the Swedish physicist Walodi Weibull in 1939 [6]. The Weibull distribution is widely used in wind energy studies because of its approach which is considered suitable and accurate to describe wind speed variations even with very small samples [7]. The potential use of wind energy as a power plant can be realized if it meets sufficient wind speed analysis data using certain methods [8].

The purpose of this study is to determine the characteristics of wind speed as a power plant expressed in the Weibull probability distribution curve. As well as knowing the form factor $(k)$ and scale factor $(c)$ of the Weibull probability curve as a feasibility reference and turbine selection, then the wind can be utilized as green energy to power safety lights and sign on the site.

\section{Methodology}

\subsection{Location Overview and Measurement}

Wind speed measurements are carried out on limestone mining quarry namely Karang Putih Hill, there are about

\footnotetext{
* Corresponding author: imran@eng.unand.ac.id
} 
10 kilometers of existing hauling road on different altitudes. In this study, the wind speed was measured at 260 meters above sea level altitude, at the waist of the hill. Not far from the beach, about 13 kilometers away, topologically Karang Putih Hill located in Padang City, West Sumatera Province, Indonesia at $\left(0^{\circ} 58^{\prime} 23.88^{\prime \prime} \mathrm{S}\right.$ and $100^{\circ} 28^{\prime} 15.88^{\prime \prime}$ E) and imaged by Google Earth software in Fig. 1.

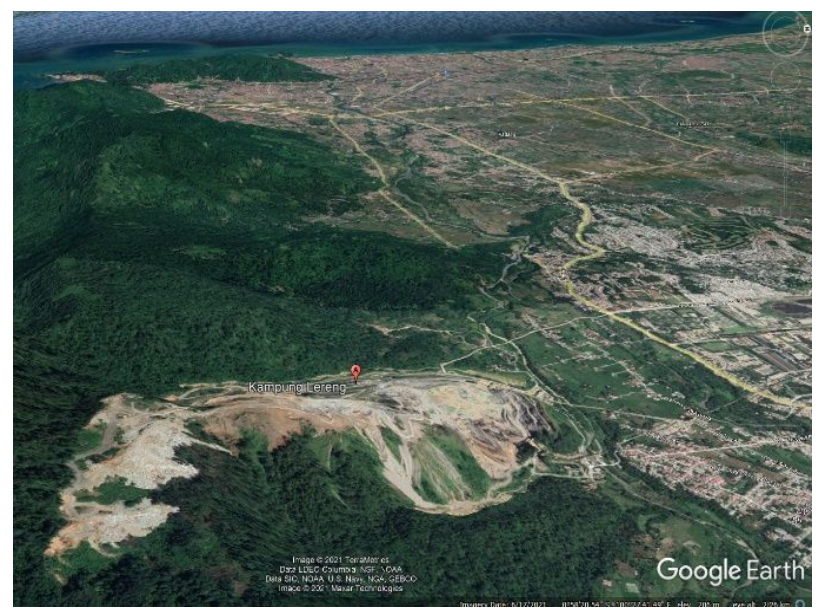

Fig. 1. Karang Putih Hill imaged by Google Earth

The data needed are wind speed, daily air temperature, and air pressure. they were measured over 30 days (February 2021 - March 2021) at the one-minute interval. Wind speed was measured using a 3-cup anemometer. The resolution of the wind speed measurement is $0.1 \mathrm{~m} / \mathrm{s}$. The accuracy according to the manufacturer's specifications is $\pm 3 \%$ over a speed range of 0 - $30 \mathrm{~m} / \mathrm{s}$. For temperature and humidity were measured using the DHT11 temperature sensor module. These sensors are connected to the data logger system using Arduino Uno microcontroller, depicted by Fig. 2, and then placed at 10 meters from the ground. Furthermore, data analysis was carried out.

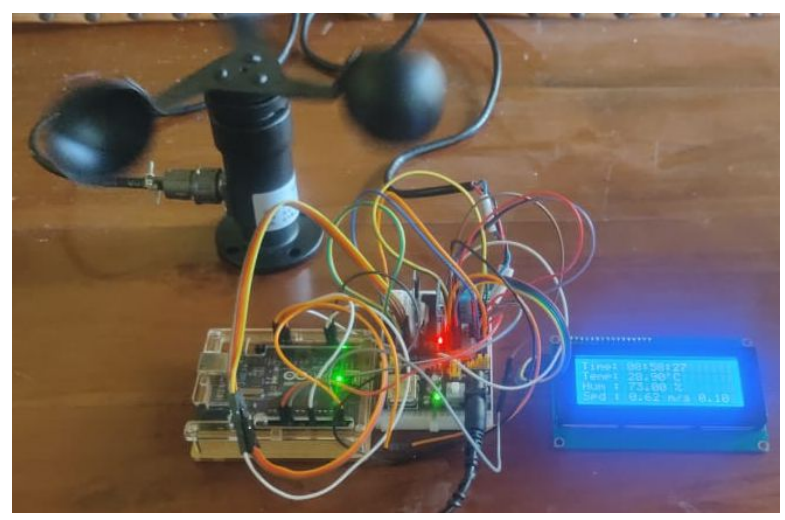

Fig. 2. Hardware for wind measurement

\subsection{Wind Data Assessment}

Besides wind speed, air density also affects wind power. First, by measuring the altitude of the site, can get vertical air pressure. The higher elevations have lower air pressure because air has mass and is influenced by the earth's gravity-based on Torricelli's Law. In addition, horizontal air pressure by air temperature also affects air density, the cold air temperature has solid mass and the hot air temperature has floating mass. The air density, air temperature, and air pressure values are related and can be obtained from the following equation [9]:

$$
\begin{gathered}
\rho=\frac{P}{R T}\left(\mathrm{~kg} / \mathrm{m}^{3}\right) \\
P=760-\frac{h}{100} \times 133(P a)
\end{gathered}
$$

$(P),(R),(T)$, and $(h)$ are air pressure, specific gas constant, ambient air temperature in Kelvin, and location altitude above sea level, respectively.

The wind is a developing atmospheric condition, its parameters change with time, therefore it is suitable to be calculated using probability density function (PDF). The probability density functions include; Weibull, Reyleigh, Gamma, Lognormal, Exponential, and Gausian [8][10]. In various literature, Weibull is the best method in determining wind energy potential [5], as follows:

$$
f(v)=\frac{k}{c}\left(\frac{v}{c}\right)^{k-1} \exp \left[-\left(\frac{v}{c}\right)^{k}\right]
$$

Where $f(v),(k)$, and $(c)$ are Weibull probability density functions in wind speed, shape parameter, and scale parameter respectively. A greater value of $(k)$, will make a higher wind amount or wind speed duration and vice versa. The value of (c) affects the maximum and minimum values of wind speed. A greater value of $(c)$, will make the curve shows high wind speed [11]. While the cumulative density function (CDF) of the Weibull distribution is as follows [9]:

$$
F(v)=1-\exp \left[-\left(\frac{v}{c}\right)^{k}\right]
$$

The Weibull distribution is a useful function in analyzing reliability and maintenance. The value of the shape and scale parameters according to the Weibull distribution is very important in choosing a wind turbine installation location [12]. There are several methods for determining the parameter $(k)$ and $(c)$ of the Weibull distribution, namely empirical method, energy pattern factor method, graphic method, moment method, maximum likelihood method, maximum likelihood modification, and equivalent energy method [13]. This research uses an empirical method in which $(k)$ value can be determined directly only by requiring the value of the average wind speed and standard deviation [14], after that we can get the value of $(c)$ as in the following equation:

$$
\begin{aligned}
& k=\left(\frac{\sigma_{V}}{v_{m}}\right)^{-1,086} \\
& c=\frac{v_{m}}{\Gamma\left(1+\frac{1}{k}\right)}
\end{aligned}
$$


Where $\sigma_{v}$ and $v_{m}$ are the standard deviation of the wind speed data and the average wind speed respectively. The ratio $v_{m}$ represents the average turbulence intensity of the area. For $\Gamma()$ is Stirling's approximation of a gamma function [15] and can be calculated by the equation [16]:

$$
\Gamma(y)=\int_{0}^{\infty} e^{-x} x^{y-1} d x
$$

The wind is air movement and has kinetic energy [17][18]. The power from the wind per unit area can be obtained by the equation (8) Meanwhile the instantaneous power generated from a wind turbine depends on the kinetic energy of the wind and the efficiency of the turbine by equation (9) as follows:

$$
\begin{gathered}
P(v)=\frac{1}{2} \rho A v^{3} \\
P_{t u r b}(v)=C_{p} \frac{\rho A v^{3}}{2}=C_{p} \frac{\pi \rho d^{2} v^{3}}{8}
\end{gathered}
$$

Where $A, \rho$, and $P_{\text {turb }}$ are turbine sweep area, air density, and turbine output power at wind speed $(v)$. Then $C_{p}$ is the overall wind turbine power coefficient, consisting of electrical efficiency, mechanical efficiency, and aerodynamic efficiency (Betz coefficient: 0.593) and $d$ is propeller diameter [19].

To analyze the wind energy potential in a region at a period, two parameters should be known;

they are power density and energy density respectively [20]. The wind power density (WPD) is the amount of power or power produced per turbine sweep area and wind energy density (WED) is an estimation of average wind turbine output power over the period, for example, one year or one month [21][22][23]. They are obtained from the equation (10) and (12). The average WPD for the Weibull distribution can be obtained from equation (11).

$$
\begin{gathered}
W P D=\frac{P(v)}{A}=\frac{1}{2} \rho v^{3} \\
W P D=\int_{0}^{\infty} P_{\text {out }}(v) f(v) d v \\
=\int_{0}^{\infty} \frac{1}{2} \rho v^{3} f(v) d v \\
=\frac{1}{2} \rho c^{3} \Gamma\left[1+\frac{3}{k}\right] \\
W E D=T \int_{0}^{\infty} P(v) f(v) d v \\
W E D=\frac{1}{2} \rho c^{3} \Gamma\left[1+\frac{3}{k}\right] T
\end{gathered}
$$

Where $P_{\text {out }}(\mathrm{v})$ is the instantaneous output power at wind speed $(v), f(v)$ is the frequency of the wind speed $(v)$ (from the appropriate wind speed distribution measurement in the form of a PDF value for a certain period). ( $T$ ) here is the period for which the average power output of $\mathrm{P}_{\text {turb }}$ is estimated, for example, one month $\mathrm{T}=$ 730 hours or one year $\mathrm{T}=8760$ hours.

Assessment of the speed and potential wind energy parameters by considering the reference from LAPAN [21] class/scale table as the minimum and maximum limits of wind energy that can be utilized for electrical energy, resulting in the assumption of modified parameters as shown in Table 1.

Table 1. Turbine scale based on minimum wind speed

\begin{tabular}{|c|c|c|}
\hline Turbine Scale & $\begin{array}{c}\text { Wind Speed } \\
\text { Minimum (m/s) }\end{array}$ & $\begin{array}{c}\text { Blade Diameter } \\
(\mathbf{m})\end{array}$ \\
\hline Very Small & 1,5 & 2 \\
\hline Small & 2,6 & 5 \\
\hline Medium & 4,1 & 20 \\
\hline Big & 5,1 & 50 \\
\hline
\end{tabular}

\section{Result and Discussion}

Three points of analysis will determine the wind potential value of a site, they are air density, wind speed variation, wind power, and wind energy density.

\subsection{Air Density}

Using equations (1) and (2), the average daily air density is between $1.19 \mathrm{~kg} / \mathrm{m}^{3}$ to $1.14 \mathrm{~kg} / \mathrm{m}^{3}$. Fig. 3 is the comparison of air density with ambient air temperature. Higher air temperature results in lower air density.

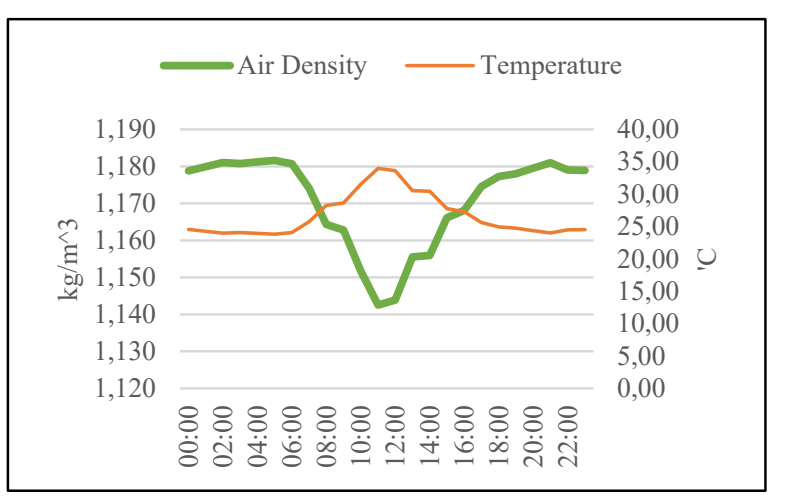

Fig. 3. Daily air density based on daily air temperature.

\subsection{Wind Speed Variation}

Wind data were collected for one month in February 2021. The whole daily average and daily powerful wind speed are graphed in Fig. 4 and Fig. 5. They show the highest average daily wind speed is at 10:00 to $15: 00$, and the lowest average daily wind speed is at 19:00 evening and 02:00 midnight. It means this site often gets wind gusts in the nighttime more than $2 \mathrm{~m} / \mathrm{s}$.

Table 2 is the result of measuring the number of wind speed frequencies that occur during one month. The obtained speed range of $1.5 \mathrm{~m} / \mathrm{s}$ is the most frequent wind speed. Statistically from the data can be obtained the average wind speed is $1,49 \mathrm{~m} / \mathrm{s}$. Furthermore, to determine the Weibull distribution, it takes the value of the shape parameter $(k)$ and the scale parameter $(c)$. These parameters will be used to determine the potential for wind power and energy in the site. But these parameters 
will vary according to time and location, as well as wind speed over time.

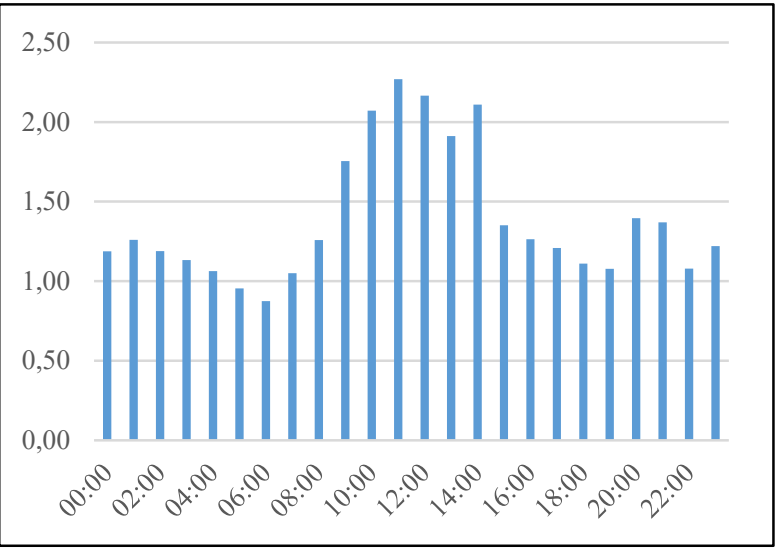

Fig. 4. Daily average wind speed in February 2021.

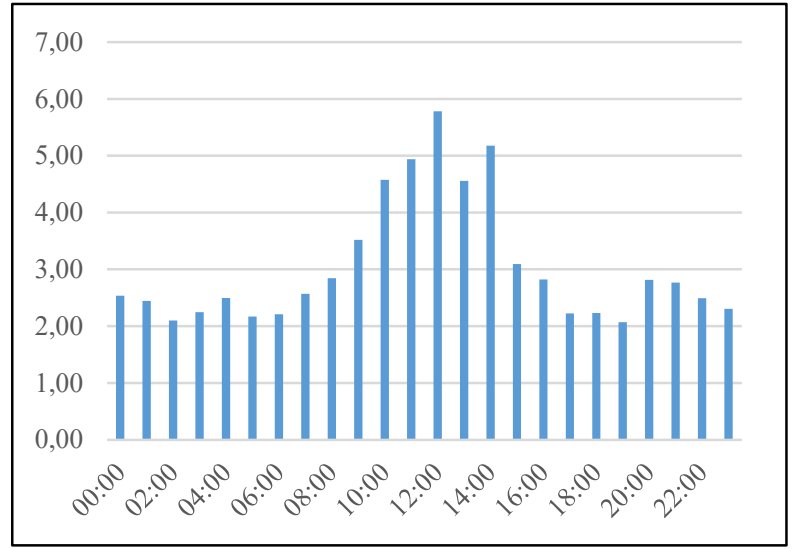

Fig. 5. Daily powerful wind speed in February 2021.

By using equations (5) and (6) the parameters of the Weibull distribution are obtained. They are 1,71 for $(k)$ value and 1,67 for $(c)$ value. Then by using equations (3) and (4), the probability density function (PDF) and the cumulative density function (CDF) can be determined which is graphed in Fig. 5.

Table 2. Weibull distribution calculation results.

\begin{tabular}{|c|c|c|c|c|}
\hline $\begin{array}{c}\text { Speed } \\
\text { Range } \\
(\mathbf{m} / \mathbf{s})\end{array}$ & Freq & $(\%)$ & PDF & CDF \\
\hline $\mathbf{0}$ & 79 & 0,18 & 0,00 & 0,00 \\
\hline $0-0,5$ & 4775 & 11,16 & 0,33 & 0,04 \\
\hline 0,5 - 1 & 8952 & 20,92 & 0,44 & 0,22 \\
\hline $1-1,5$ & 12277 & 28,68 & 0,40 & 0,46 \\
\hline $1,5-2$ & 8031 & 18,76 & 0,31 & 0,66 \\
\hline $2-2,5$ & 3922 & 9,16 & 0,22 & 0,81 \\
\hline $2,5-3$ & 2078 & 4,86 & 0,14 & 0,9 \\
\hline $3-3,5$ & 1166 & 2,72 & 0,08 & 0,96 \\
\hline $3,5-4$ & 624 & 1,46 & 0,05 & 0,98 \\
\hline $4-4,5$ & 361 & 0,84 & 0,03 & 0,99 \\
\hline $4,5-5$ & 227 & 0,53 & 0,02 & 1,00 \\
\hline $5-5,5$ & 167 & 0,39 & 0,01 & 1,00 \\
\hline $5,5-6$ & 40 & 0,09 & 0,01 & 1,00 \\
\hline $6-6,5$ & 72 & 0,17 & 0,00 & 1,00 \\
\hline$>6,5$ & 29 & 0,07 & 0,00 & 1,00 \\
\hline
\end{tabular}

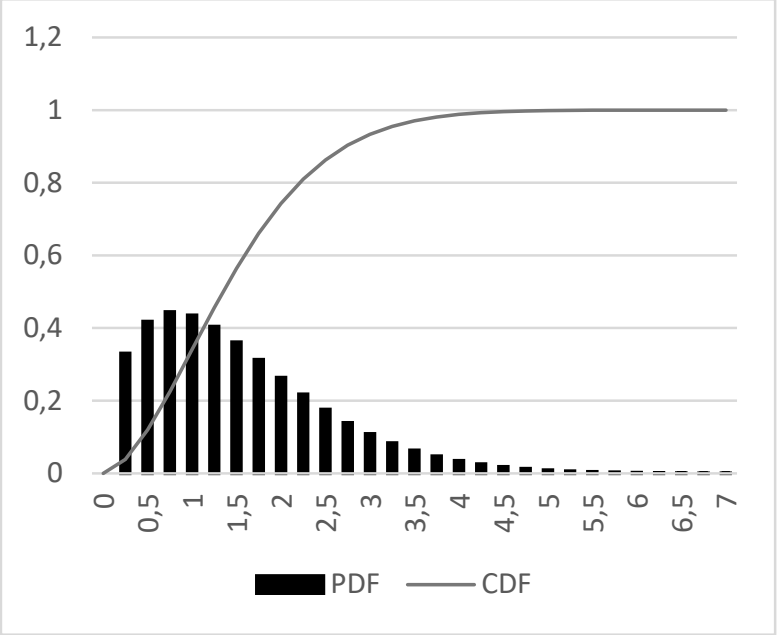

Fig. 5. PDF and CDF chart.

\subsection{Wind Power and Energy Density}

Based on the data obtained from the wind speed distribution, then the calculation of the potential power and wind energy per month is carried out with equations (10) and (12) so that the results are obtained in Table 3. The potential for wind power and energy at this location is $3,14 \mathrm{~W} / \mathrm{m}^{2}$ and $2,26 \mathrm{kWh} / \mathrm{m}^{2}$ when using a turbine with a $1 \mathrm{~m}^{2}$ sweep area. Based on Table 1 and the analysis result, the wind potential of this site can be utilized by using very small and small wind turbine scales. As a result, monthly wind energy can be obtained effectively of 7,10 to $44,37 \mathrm{kWh} / \mathrm{m}^{2}$. Table 4 gives example for using various wind turbine blades or rotor diameters.

Table 3. Analysis result of wind power potential.

\begin{tabular}{|c|c|c|c|c|c|}
\hline \multirow{2}{*}{$\begin{array}{c}\rho \\
\left(\mathrm{kg} / \mathrm{m}^{3}\right)\end{array}$} & \multicolumn{2}{|c|}{ Parameter } & \multirow{2}{*}{$\begin{array}{c}\text { Mean } \\
(\mathrm{m} / \mathrm{s})\end{array}$} & \multirow{2}{*}{$\begin{array}{c}\text { WPD } \\
\left(\mathbf{W} / \mathbf{m}^{2}\right)\end{array}$} & \multirow{2}{*}{$\begin{array}{c}\text { WED } \\
\left(\mathrm{kWh} / \mathrm{m}^{2}\right)\end{array}$} \\
\hline & $\mathbf{k}$ & c & & & \\
\hline 1,17 & 1,71 & ,67 & 1,49 & 3,14 & 2,26 \\
\hline
\end{tabular}

Table 4. Wind power density and wind energy density monthly achieved based on various wind turbine blade diameter

\begin{tabular}{|c|c|c|}
\hline $\begin{array}{c}\text { Rotor Diameter } \\
(\mathbf{m})\end{array}$ & $\begin{array}{c}\text { WPD } \\
\left(\mathbf{W} / \mathbf{m}^{\mathbf{2}}\right)\end{array}$ & $\begin{array}{c}\text { WED } \\
\left(\mathbf{k W h} / \mathbf{m}^{\mathbf{2}} \mathbf{)}\right.\end{array}$ \\
\hline 1 & 2,46 & 1,77 \\
\hline 2 & 9,86 & 7,10 \\
\hline 3 & 22,18 & 15,97 \\
\hline 4 & 39,44 & 28,40 \\
\hline 5 & 61,62 & 44,37 \\
\hline
\end{tabular}

\section{Conclusion}

This study focuses on wind potential assessment used for safety lights and signs on mining hauling roads in Karang Putih Hill. Based on shape and scale parameters, can we infer that wind characteristic in the hauling road at 260 meters altitude has regular wind gust with low to medium wind speed variation? So that the analysis results of air density, wind variation, and wind power density, this site has the potential to utilize wind energy by using up to a small turbine scale. 
The authors would like to express gratitude to the Electrical Engineering Department of Andalas University for providing publication support under Publication Grant Scheme (No. 79/UN.16.09.D/PL/2021)

\section{References}

1. Institute of Electrical and Electronics Engineers, "2016 2nd International Conference of Industrial, Mechanical, Electrical, and Chemical Engineering (ICIMECE) : October, 6-7, 2016, Royal Ambarrukmo Hotel, Yogyakarta, Indonesia., "196200 (2016)

2. E. Sun and X. Zhang, "3D assisted driving system for haul trucks in surface mining," Proc. 2011 Int. Conf. Transp. Mech. Electr. Eng. TMEE 2011, 363-366, (2011)

3. Y. Nishimura, T. Osafune, S. Kato, A. Hiromori, H. Yamaguchi, and T. Higashino, "Vehicle Proximity Awareness by Inter-Vehicle Communication for Surface Mine Operation Safety," IEEE Veh. Technol. Conf., 2017-June (2017)

4. E. Sun, "The fuzzy neural network based haul truck driver fatigue detection in surface mining," ICNCFSKD 2017 - 13th Int. Conf. Nat. Comput. Fuzzy Syst. Knowl. Discov., no. 2016, pp. 1522-1526 (2018)

5. M. B. Hemanth Kumar, S. Balasubramaniyan, S. Padmanaban, and J. B. Holm-Nielsen, "Wind energy potential assessment by Weibull parameter estimation using multiverse optimization method: A case study of Tirumala region in India," Energies, 12, 11 (2019)

6. L. G. Otaya, "Distribusi Probabilitas Weibull Dan Aplikasinya," J. Manaj. Pendidik. Islam, 4, 2, pp. 4466 (2016)

7. E. Parameter and I. Tsani, "Estimasi Parameter ... (Indria Tsani),'27-35.

8. J. Waewsak, C. Chancham, M. Landry, and Y. Gagnon, "An Analysis of Wind Speed Distribution at Thasala, Nakhon Si Thammarat, Thailand," $J$. Sustain. Energy Environ., 2, no. January, 51-55, (2011)

9. Z. H. Hulio, W. Jiang, and S. Rehman, "TechnoEconomic Assessment of the wind power potential of Hawke's Bay using Weibull parameter: A review," Energy Strateg. Rev., 26, no. February, 100375 (2019)

10. O. Douglas Queiroz de Oliveira Filho et al., "Analysis of Weibull parameters for wind power generation," no. March 2018 (2018)

11. Ilyas, Suriadi, and M. Gapy, "Analisis Potensi Tenaga Angin Menggunakan Metode Distribusi Weibull di Kawasan Banda Aceh," Semin. Nas. dan Expo Tek. Elektro, no. February, 66-68 (2017)
12. P. Bhattacharya, "Weibull Distribution for Estimating the Parameters," Wind Energy Manag., no. 1 (2011)

13. S. Deep, A. Sarkar, M. Ghawat, and M. K. Rajak, "Estimation of the wind energy potential for coastal locations in India using the Weibull model," Renew. Energy, 161, 319-339 (2020)

14. C. F. De Andrade, H. F. Maia Neto, P. A. Costa Rocha, and M. E. Vieira Da Silva, "An efficiency comparison of numerical methods for determining Weibull parameters for wind energy applications: A new approach applied to the northeast region of Brazil," Energy Convers. Manag., 86, 801-808 (2014)

15. S. L. Walker, "Building mounted wind turbines and their suitability for the urban scale-A review of methods of estimating urban wind resource," Energy Build., 43, 8, 1852-1862 (2011)

16. R. Maouedj et al., "Wind energy resource assessment at three sites in the Algerian highlands," Proc. 2018 6th Int. Renew. Sustain. Energy Conf. IRSEC 2018, pp. 0-5 (2018)

17. A. Serban, L. S. Paraschiv, and S. Paraschiv, "Assessment of wind energy potential based on Weibull and Rayleigh distribution models," Energy Reports, 6, April, 250-267 (2020)

18. F. Oral, I. S. Ekmekçi, and N. Onat, "Weibull distribution for determination of wind analysis and energy production," World J. Eng., 12, no. 3, pp. 215-220 (2015)

19. R. D. Prasad, R. C. Bansal, and M. Sauturaga, "Wind modeling based on wind input data conditions using Weibull distribution," Int. J. Glob. Energy Issues, 32, 3, 227-240 (2009)

20. C. Paper et al., "Wind energy potential assessment to estimate the performance of selected wind turbine in the northern coastal region of Semarang-Indonesia," no. January (2017)

21. A. Fadlullah, S. Riyanto, and S. Sudirman, "Pengembangan Aplikasi Analisis Potensi Angin Sebagai Sumber Energi Terbarukan Menggunakan Estimasi Parameter Weibull Berbasis Metode Power Density (Studi Kasus: Kota Tarakan)," Inovtek Polbeng, 9, 1, 129 (2019)

22. B. S. Premono, D. D. D. P. Tjahjana, and S. Hadi, "Wind energy potential assessment to estimate the performance of selected wind turbine in the northern coastal region of Semarang-Indonesia," AIP Conf. Proc., 1788, no. January (2017)

23. M. A. Hyams, "Wind Energy in the built environment," Metrop. Sustain. Underst. Improv. Urban Environ., pp. 457-499 (2012) 